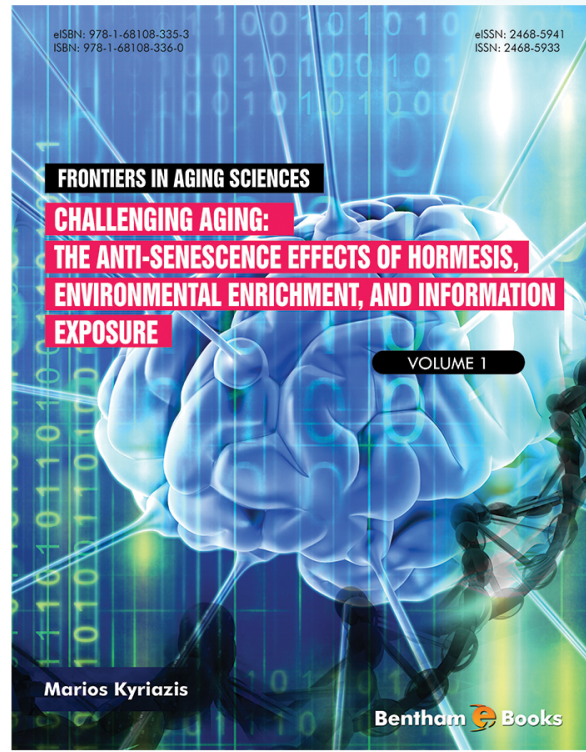

\title{
Author:
}

E-book Price

US\$ 89.00

Print-on-Demand

US\$ 107.00

Marios Kyriazis

United Kingdom

Institutional E-Book Price

US\$ 316.00

\section{elSBN: 978-1-68108-335-3}

\section{Challenging Aging: The Anti-senescence Effects of Hormesis, Environmental Enrichment, and Information Exposure}

\section{WWW.ehooks.henthamseience.com/hook/9781681083353/}

\section{About the eBook}

This volume explains the role of hormesis in anti-aging processes followed by information on vitagenes, epigenetics, environmental enrichment and germlines. The monograph also brings newer concepts and theories to the fore, such as 'environmental enrichment' and 'technoculture.'

\section{Contents}

- Hormesis and Adaptation

- Vitagenes and Hormetins: The Pills of Hormesis

- Environmental Enrichment: General Concepts and Research

- Epigenetic Regulation and Adaptation to Stimuli

- A 'War of Trade-offs' Between the Soma and the Germ Line

- Another Dimension: 'Zooming Out'

- Energy, Entropy and Complexity: Thermodynamic and Information-Theoretic Perspectives on Ageing

- Engagement with a Technological Environment for Ongoing Homoeostasis Maintenance

- Appendix

\section{For Advertising Inquiries: Contact: marketing@benthamscience.org}

